\title{
Basic science for the clinical gastroenterologist: A review of the recent literature on the small bowel - Part II
}

\author{
ABR THOMSON MD PhD FCRCP FACP FRS FACC
}

ABR THOMSON. Basic science for the clinical gastroenterologist: A review of the recent literature on the small bowel - Part II. Can J Gastroenterol $1994 ; 8(4): 261-268$. In small bowel science, as in all parts of medicine, there has been a recent explosion of information. This is the second of a two-part series in which the scientific basis of clinical gastroenterology practice and its future are considered. Advances in understanding the mechanisms of intestinal transport are examined, followed by a perspective of intestinal adaptation in health and disease. The author also discusses clinically important areas of motility and bloodflow.

Key Words: Adaptation, Carbohydrates, Ischemia, Small bowel

Science fondamentale pour le gastro-entérologue clinique : Survol de la littérature récente sur l'intestin grêle - Partie II

RÉSUMÉ : On a assisté récemment à une explosion de connaissances dans tous les domaines de la médecine et cela s'applique également aux connaissances sur l'intestin grêle. Voici la seconde d'une série de deux articles qui porteront sur les fondements scientifiques de la pratique clinique en gastro-entérologie et sur son avenir. Les connaissances acquises au sujet des mécanismes du transport intestinal seront abordées, ainsi que l'adaptation de l'intestin aux situations normales et morbides. L'auteur traitera également de thèmes importants sur le plan clinique, relativement à la motilité et à la circulation sanguine.

D EALING WITH CARBOHYDRATES, dietary starch is digested by pancreatic amylase into maltose, maltotriose, maltotetrose and maltopentose.
Continuing hydrolysis of these glucose polymers arises from the activity of glucoamylase and sucrase-isomaltase, which together remove glucose from

Nutrition and Metabolism Research Group, Division of Gastroenterology, Department of Medicine, University of Alberta, Edmonton, Alberta

Correspondence and reprints: Dr ABR Thomson, 519 Robert Newton Research Building, University of Alberta, Edmonton, Alberta T6G 2C2. Telephone (403) 492-6490, Fax (403) $492-7964$

Received for publication May 27, 1993. Accepted August 25, 1993

the nonreducing end of the polymers. Acarbose is a potent inhibitor of amylase, glucoamylase and sucrase (alphaglucosidases). Acarbose does not interfere with glucose transport, but can be used to uncouple digestion from absorption (1). Mucosal-to-serosal flux of polymer-derived glucose is lower in acarbose-treated rabbit jejunal seg. ments studied under short circuited conditions in vitro, suggesting that hydrolyses may limit glucose polymer assimilation.

Species comparisons among mammals yield the striking observation that the area of the whole length of the small intestine at the microvillus level varies nearly linearly as the mammal's metabolic liver mass increases (2) (Figure 1). The capacity of the intestine for taking up nutrients normally exceeds prevailing nutrient intakes by only a small safety margin (3) (Figure 2). This safety margin or reserve capacity is relatively large when mice are kept at $22^{\circ} \mathrm{C}$, but the safety margin becomes much less when the mice are at $6^{\circ} \mathrm{C}$ before intestinal adaptation begins to occur.

It is important to know the physiological concentration of glucose in the small intestine to understand better the mechanisms and the potential relevance of adaptation of intestinal transport. Diamond and co-workers (4) 


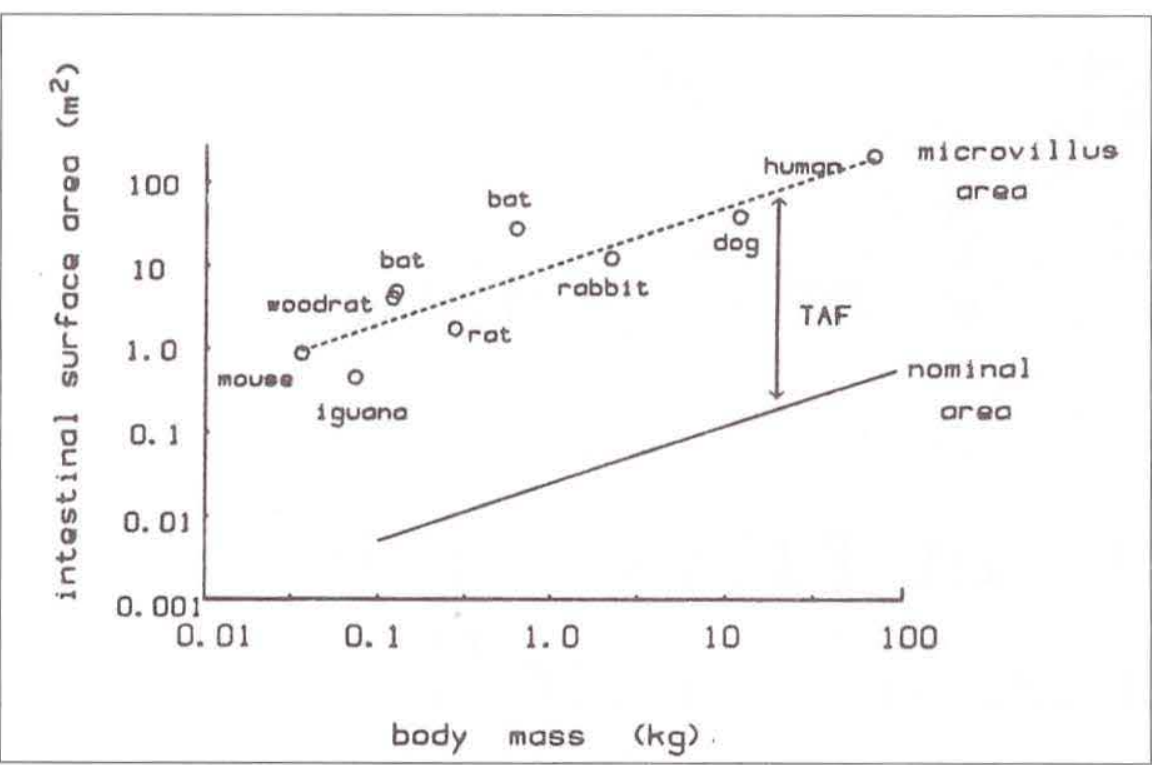

Figure 1) Double logarithmic plot of total surface area of the whole length of the small intestine at the microvillus level as a function of body mass for nine species. Reproduced with permission from reference 2. TAF Total amplification factor

measured luminal glucose concentrations in normally feeding rats, rabbits and dogs. The osmolalities of luminal contents were $100 \mathrm{mOsm} / \mathrm{kg}$ or less hypertonic, and glucose concentrations averaged from 0.4 to $24 \mathrm{mM}$ (range 0.2 to 48). The effective Michaelis constant $(\mathrm{Km})$ of glucose transport (about $1 \mathrm{mM}$ ) is comparable to prevailing glucose concentrations; indeed, there appears to be only a small excess of small intestinal absorptive capacity for glucose. This is also compatible with the frequently reported observations that intestinal adaptation is usually associated with an altered value of the maximal transport rate $(V \max )$ rather than the $\mathrm{Km}$. In mice, activities of the glucose and fructose transporters are upregulated by increased levels of dietary carbohydrate, and transporters for the amino acids proline and aspartate are upregulated by increased levels of dietary protein. The small intestine is also capable of adapting the activity of carbohydrases to dietary carbohydrate intake (5), and the increases in both sucrase-isomaltase and maltase-glucoamylase activities are seen in cells all along the length of the villus column (when activities are expressed on the basis of the DNA content of the cell fractions). The regulation of glucose transport by dietary intake of carbohy- drate 'now makes functional sense'. Thus, upregulation of glucose transport (increased $V \max$ ) serves to match uptake capacity to dietary intake.

In carnivores, only the mink is able to regulate sugar transporter activity in response to changes in the levels of dietary carbohydrate, whereas this is not possible in the cat or the frog. All three species are able to regulate their rates of amino acid transport, which is understandable considering that strict carnivores consume natural diets that are predictably high in protein with negligible carbohydrate levels (6); thus "the ability of a species to regulate its intestinal brush-border nutrient transporters in response to changes in dietary composition has been programmed during evolution by the natural diet".

Based on kinetic arguments, it has been proposed that there are two distinct sodium/D-glucose cotransporters in brush border membrane (BBM) vesicles isolated from the human fetal jejunum (7): a low affinity, high capacity system and a high affinity, low capacity system. These are thought to be present during early gestation, and are differentiated by their kinetic properties and by differences in both their substrate and inhibitor specificities (8). A fast sampling, rapid filtration apparatus has been developed to study D-glucose transport in jejunal BBM vesicles from young animals (9). The high affinity, low capacity and the low affinity, high capacity pathways could be separated by different kinetic criteria - by sodium: hexose stoichiometry and by sensitivity to inhibitors. In contrast, in adult human intestinal BBM vesicles, only one sodium-dependent transport pathway was found (10). Nonetheless, some workers (11) continue to find evidence of two glucose transporters in the intestine of adult animals.

The rat BBM undergoes a maturational process in terms of its physical properties as the enterocyte migrates up the villus, with the more mature cells in the villus tip being less fluid (ie, more rigid) due to both an increase in the cholesterol:phospholipid ratio and to alterations in individual phospholipid subclasses (12). The maximal transport rate for glucose is highest in cells near the upper, compared with the lower, portion of the crypt-villus axis.

D-xylose absorption may reflect mucosal permeability and surface area, and the use of the glucose analogue 3-0. methyl-D-glucose (3-MG) has been used to assess sodium-dependent, phlorizin-sensitive glucose uptake (13): 3-MG absorption is reduced in methotrexatetreated rats with small bowel mucosal injury, whereas damage could not be detected using mannitol or polyethylene glycol.

The topic of the molecular biology of intestinal glucose transport has been reviewed (14). Glucose is transported across the enterocytes by a sodiumdependent uptake step across the BBM and by a facilitative glucose step across the basolateral membrane (BLM) (Figure 3$)$. Wright and colleagues $(15-17)$ have cloned and sequenced the rabbit intestinal sodium/glucose cotransporter. This sodium-dependent glucose transporter-1 (SGLT1) is responsible for active glucose transport across the intestinal BBM, and is distinct from the two facilitative glucose transporters: glucose transporter-2 (GLUT2) for glucose in the BLM and GLUT5 for fructose in the BBM. GLUT2 2 and GLUT5 are on chromosomes 1 and 3 , whereas SGLT 1 is on chromosome 22 (18). The SGLT1 is electrogenic, and the membrane poten- 
tial influences the maximal velocity of the transporter $\left(V_{\max }\right)$, as well as the binding constants for sodium and for glucose (19). This cotransporter is a polypeptide with a molecular weight of 70,000 to 75,000 and the cloned cotransporter has a predicted molecular mass of $73 \mathrm{kDa}$. The SGLT 1 functions in the $\mathrm{BBM}$ as a $290 \mathrm{kDa}$ homotetramer comprised of four independent $73 \mathrm{kDa}$ subunits (20).

There is homology between SGLT and the Escherichia coli proline carrier, but not with the E coli melibiose transporter (16); this indicates an evolutionary link between bacterial and human sodium cotransport proteins. At the DNA level and at the levels of the predicted amino acid and secondary structure, there is an $82 \%$ homology between the human and rabbit intestinal sodium/glucose cotransporter. This close similarity at the DNA level between the sequences of the rabbit and human SGLT 1 clone is reflected in the results of Northern blot analysis of human and rabbit mRNA. The deduced amino acid sequence was analyzed for potential membrane-spanning regions using the hydrophobic moment analysis (Figure 4), and a 12-latex configuration has been proposed.

The SGLT1 in the BBM bears no sequence similarity to the sodium-independent, facilitated glucose carrier (GLUT2) found in the BLM of epithelial cells (21). The cDNA encoding the SGLT1 from rabbit jejunum has been used to examine the distribution of homologous mRNA in other rabbit tissues. Northern blots of mRNA extracted from various tissues have been probed with radiolabelled cDNA at the cloned rabbit transporter (22). The sodium/glucose cotransporter of rabbit renal cortex is very similar to the SGLT1 of the small intestine. All regions of the small intestine show a predominant mRNA transcript at about $2.3 \mathrm{~kb}$ that hybridizes to the probe. The signal is strongest in the jejunum, followed by the ileum and duodenum, with only trace amounts present in the colon of adult animals. The high DNA sequence identity between the renal and intestinal clones indicates that these may be products of the same gene. Hybridization between
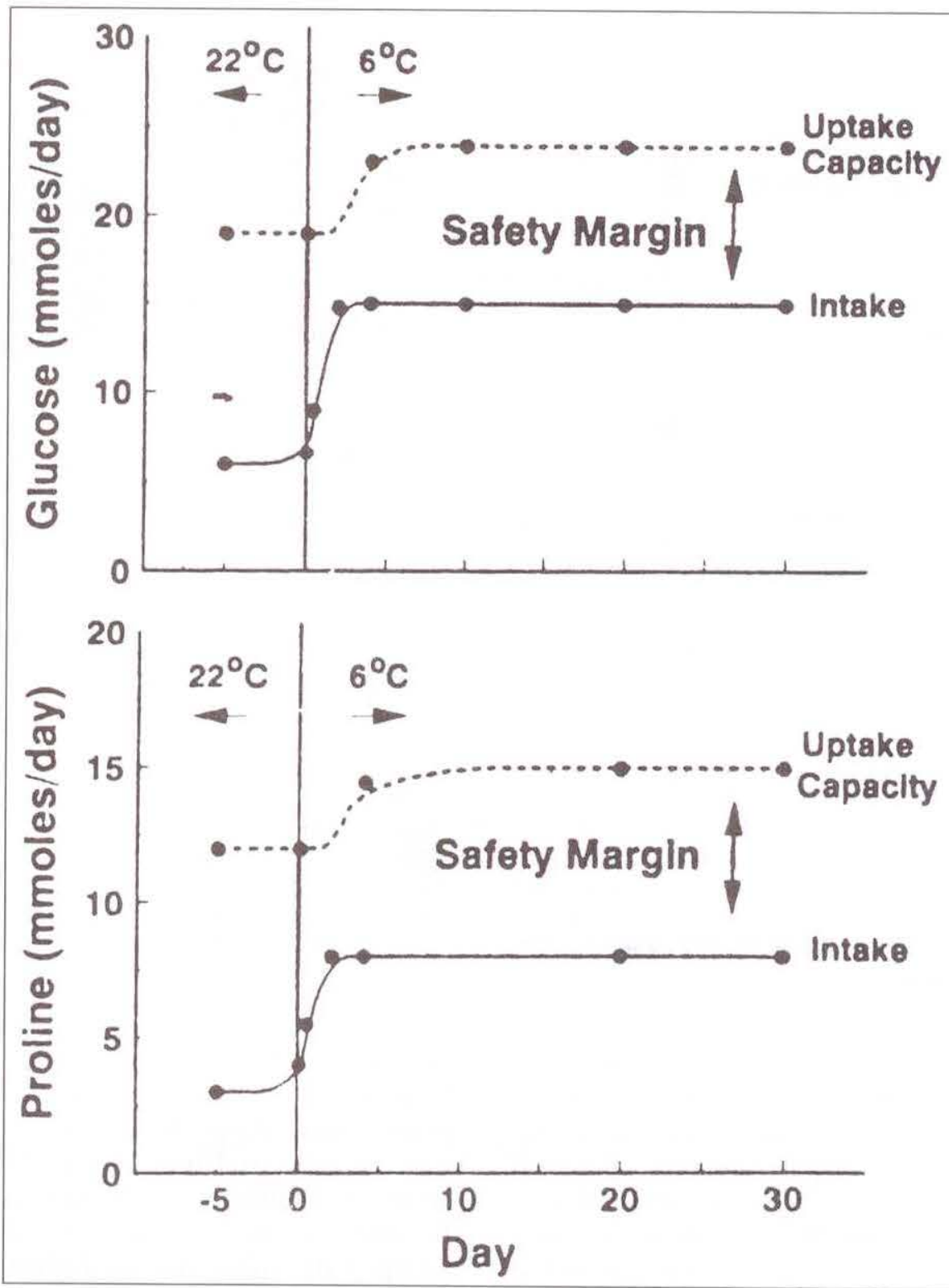

Figure 2) Safety margins for D-Glc and L-Pro uptake, defined as the reserve by which uptake capacity exceeds dietary intake. Reproduced with permission from reference 3

intestinal mRNA and the rabbit intestinal SGLT 1 CDNA has been seen in most species.

Cultured epithelial cell lines have been used as models of intestinal function; sodium-dependent hexose transport occurs in cultured Caco-2 cell layers grown on permeable support (23), but culture conditions have a profound effect on the morphological appearance and transport indices of these cells. The Cos-7 cell line does not normally express the sodium-dependent glucose transporter, but when it is transfected with the CDNA coding for the transporter, the COS-7 cells express all the properties of the 'classical' glucose transporter (24). While the injection of in vitro synthesized RNA from the rabbit small intestinal clone into Xenopus laevis oocytes has been useful in studying the electrophysiological properties of the glucose carrier, some of the posttranslational events, such as glycosylation, phosphorylation and/or subunit assembly, may not be the same in amphibian oocytes as in mammalian cells.

The cloned intestinal sodium/glucose cotransporter has been studied further with antibodies against peptides synthesized from different regions of the predicted primary amino acid se- 


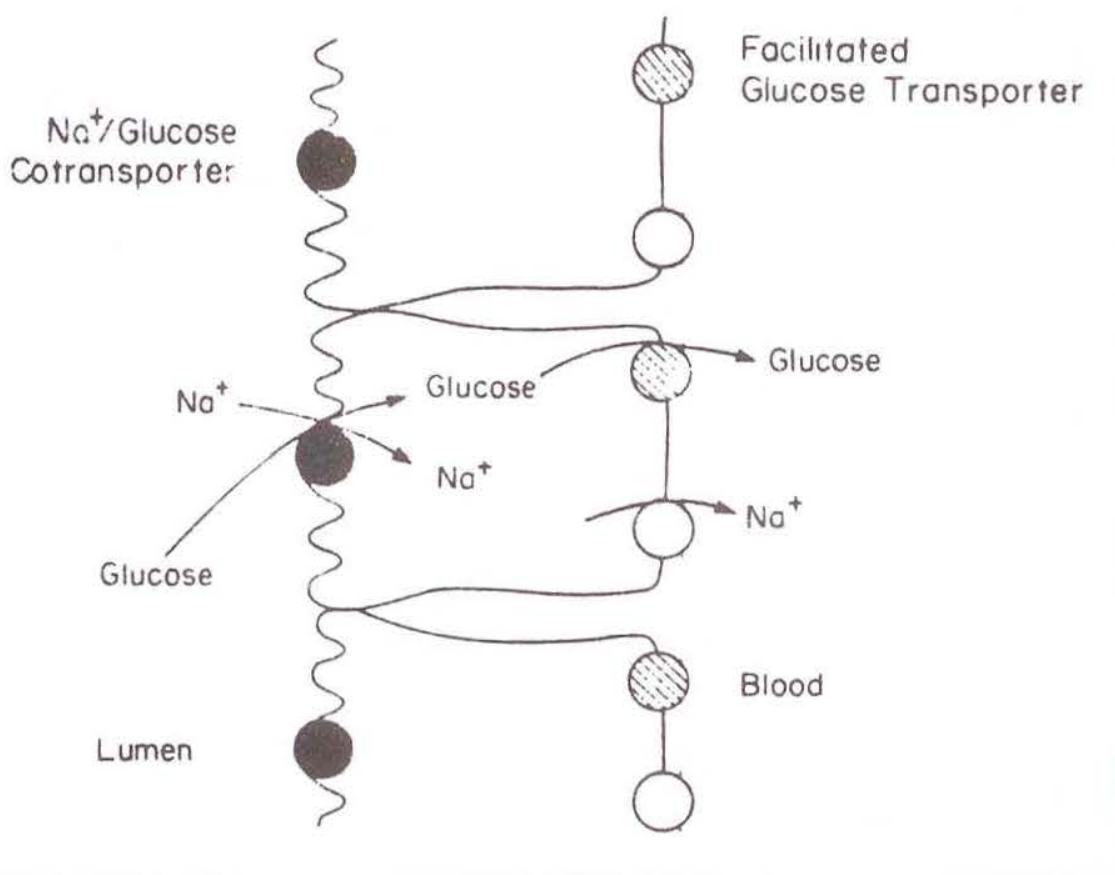

Figure 3) A simple method showing the two-stage transport of glucose (galactose) across the mature enterocytes of the small intestine. Sugar is absorbed in a two-stage process: the first is the uphill transport from lumen to cell across the brush border membrane by the cotransporter; and the second is the diffusion out of the cell across the basolateral membrane by the facilitated transporter. The cotransporter is energized by the sodium $\left(\mathrm{Na}^{+}\right)$gradient (concentration and electrical) across the $\mathrm{Na}^{+} / \mathrm{K}^{+}$-ATPase pump. The addition of sugar to the lumen, therefore, increases net absorption of sodium and water across the intestine. Reproduced with permission from reference 14

quence of the cloned intestinal transporter (25) (Figure 5). SGLT1 resides on the distal q arm of chromosome 22, and SGLT1 CDNA and genomic DNA from members of a family affected with glucose/galactose malabsorption have been amplified using the polymerase chain reaction. Sequence analysis of the amplified products revealed a single missense mutation in SGLT1, which cosegregates with the glucose/galactose malabsorption phenotype and which resulted in a complete loss of sodiumdependent glucose transport in xenopus oocytes injected with this complementary RNA (26).

With the recent advent of cDNA probes and antibodies to the $S_{G L T}$, it is possible to determine where the genes are transcribed, the mRNA translated, and the proteins inserted into the BВM and activated in order to carry out their digestive or transport functions. Immunocytochemical and in situ hybridization techniques have been used to examine the distribution of SGLT1 mRNA and protein from the crypt to villus of the rabbit small intestine (27). Transcription of the gene appears to be initiated as the enterocytes emerge from the crypt, and transcription increases as the enterocytes migrate up the villus; the mature enterocytes on the tip of the villus have the highest levels of protein and mRNA.

However, the sodium/glucose cotransporter protein is only found in the BBM of mature enterocytes towards the top of the villus. The simplest interpretation of these results is that the SGLT1 gene is transcribed, the mRNA is translated and the protein is directly inserted into the BBM of mature enterocytes, but the transporter becomes functional only in the upper portions of the villus. The possibility of a B-subunit regulator has also been considered, but further study is awaited.

Immunoreactivity in sheep BBM correlates quantitatively with the rate of sugar transport over several orders of magnitude. The immunocytochemical results of Wright and co-workers (27) for the rabbit intestine are similar to those of Takata et al (28), but both reports differ from those by Haase and colleagues (29), who prepared monoclonal antibodies that interacted with the sodium/glucose cotransporter (SGLT1) - higher concentrations of SGLT1 per membrane length were observed in the jejunum, versus the duodenum or ileum (29). In enterocytes from different parts of the villi, the cotransporters were distributed homogenously. There were different surface areas of the transporter-containing BBM per intestinal length for different segments of small intestine, and there were different densities of the transporter within the BBM. Since mature enterocytes have a larger area of BBM than immature enterocytes, the former contain more cotransporters in the luminal membrane. This difference between the three studies in the distribution of cotransporter molecules, rather than variations in their activity, may be due to differences in the specificity of the antibodies used. For example, the monoclonal antibodies of Haase and co-workers (29) reacted with both 75 and $43 \mathrm{kDa}$ proteins, while the antipeptide antibody used by Takata (28) detected only an $84 \mathrm{kDa}$ protein.

The expression of the SGLT1 may vary 100 -fold with diet, without a change in BBM enzyme activity or intestinal morphology (30). Glycosylation is sometimes needed for efficient processing and insertion of functional channel proteins into plasma membrane, but glycosylation is apparently not required for the functional expression of the sodium/glucose cotransporters in xenopus oocytes (31).

The facilitated glucose transporters form a family of structurally related proteins (32). Four different mammalian facilitated glucose transporters have been identified by molecular cloning. Each isoform appears to have a specific physiological function, and expression can be regulated in a tissue-specific manner by glucose or by insulin. The liver glucose transporter (GLUT2) is also expressed in the intestine, kidney and pancreatic islet beta cells. In the intestine, GLUT2 is on the BLM and in differentiated epithelial cells, but not on the BBM or in immature crypt cells (33). 


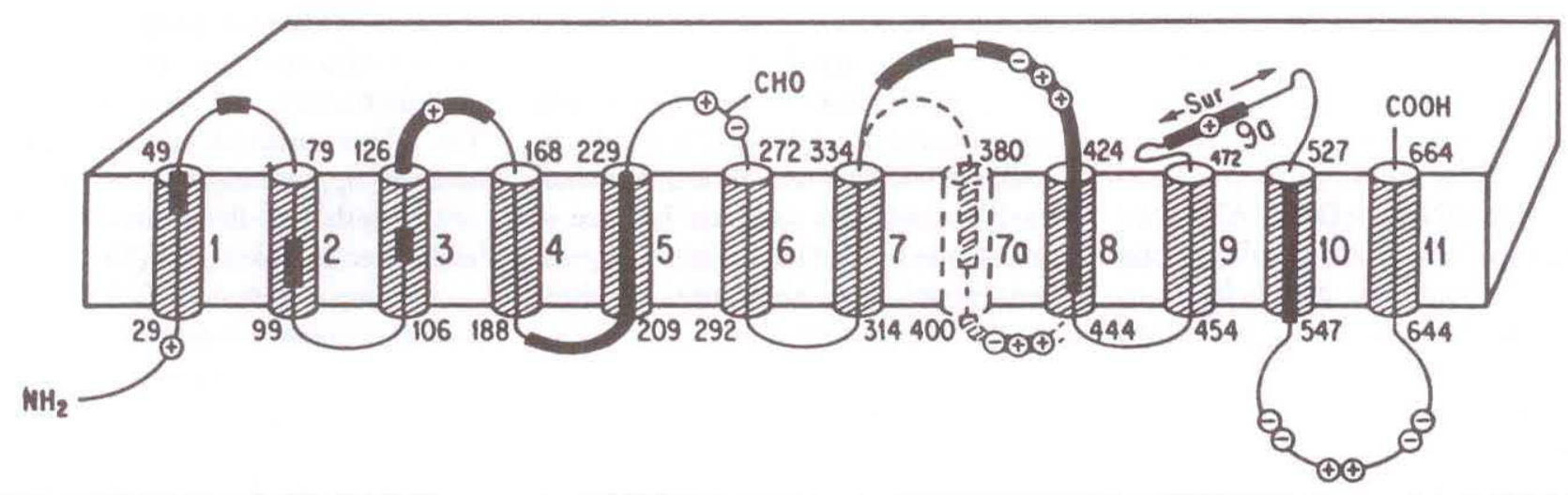

Figure 4) Proposed model of the membrane orientation of the human intestinal sodium/glucose cotransporter. The method of Eisenberg et al (J Mol Biol 1984;176:125-42) was used with windows of 21 and 11 amino acids to predict membrane-spanning segments 1 to 11 . Segment 7 a is shoun with dotted lines and represents an additional possible membrane-spanning segment. CHO indicates an N-glycosylation site. The region labelled Sur is a surface-seeking membrane region and was predicted using the Eisenberg method. Heavy lines in the sequence indicate regions of particular sequence homology with the Escherichia coli sodium/proline transporter. Clusters of negative and positive charges in the hydrophilic regions of the sequence are represented as - and + . Reproduced with permission from reference 16

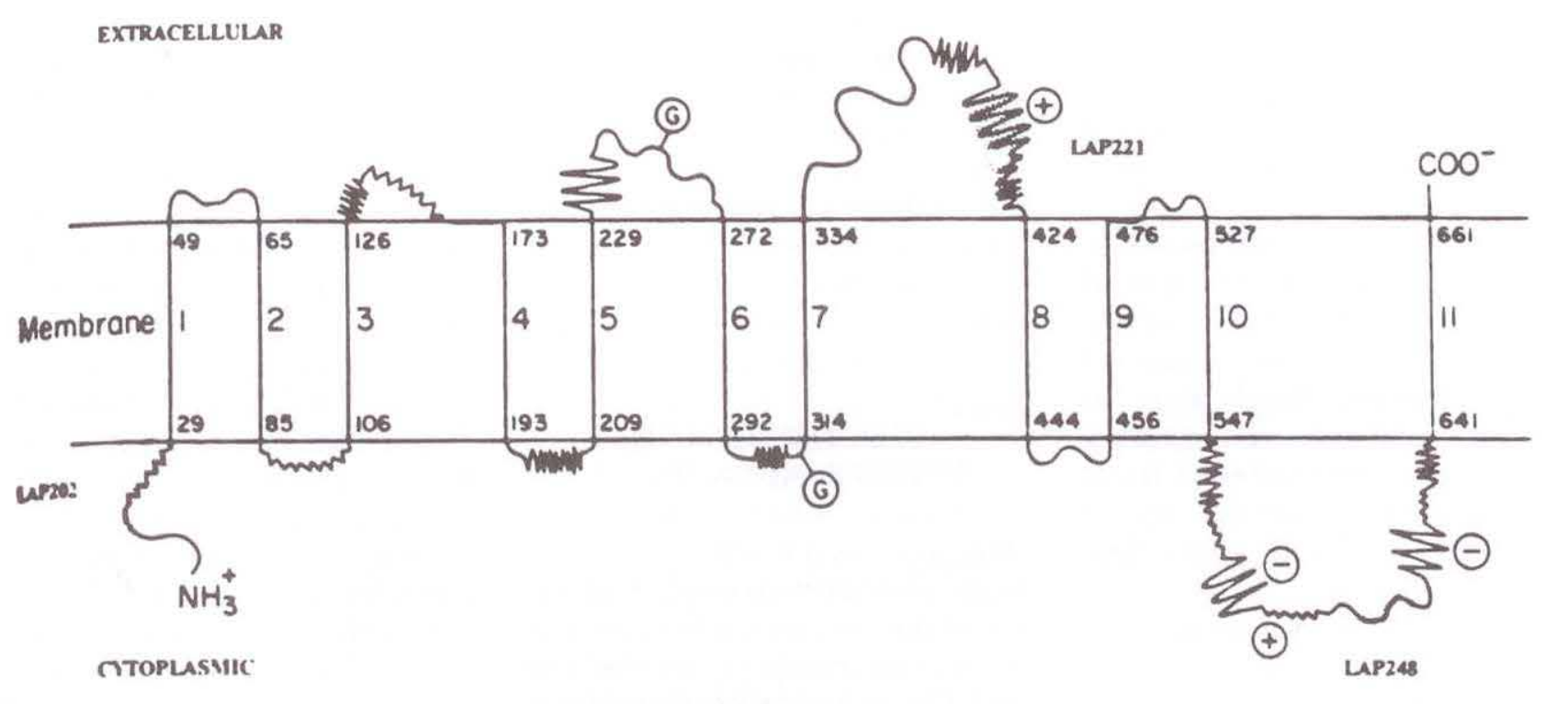

Figure 5) Location of peptides from the sodium/glucose cotransporter used for antibody production. Location of the three peptides is shown on the secondary structure model of cloned rabbit intestinal sodium/glucose cotransporter. Shaded areas represent amino acid residues 402 to 419 (peptide LAP221), residues 604 to 615 (peptide LAP248) and residues 15 to 29 (peptide LAP202). Reproduced with permission from reference 25

GLUT5, found in the BBM of the small intestine (34), has only a $40 \%$ identity with GLUT2. GLUT5 appears to represent the BBM facilitative transporter for fructose (35). The intestinal absorption of fructose appears to be greater when the fructose is ingested with glucose (36). Fructose-sorbitol malabsorption may occur in patients with the irritable bowel syndrome, but may also occur in healthy controls (37). Over-expression of three of these facilitative glucose transporter genes (GLUT1, GLUT2 and GLUT3) has been described in selected human cancers. Future studies may determine whether measurement of GLUT proteins in dysplastic colonic tissue will establish their premalignant potential (ie, low or high grade dysplasia).

Tissues of the small intestine use primarily glutamine in the fed state and ketone bodies in the starved state. Cells taken from the jejunum produced carbon dioxide from exogenous substrates in decreasing order as follows: glutamine $>$ glucose $>$ acetate, propionate and butyrate. In tissues of the large bowel, glucose, glutamine and butyrate are important respiratory fuels. In colonic cells, the decreasing order of oxidation is as follows: butyrate > acetate > propionate, glucose and glutamine (38). Enterocytes and colonocytes isolated from hypothyroid rats show decreased rates of use and metabolism of glucose and glutamine (39), possibly 
due to changes in protein turnover and/or the maximal activities of key enzymes in the pathways of glucose and glutamine metabolism in these cells.

\section{INTESTINAL ADAPTATION}

The molecular and cellular mechanisms involved in transepithelial transport have been reviewed (40). Even though there may be a 'surplus' surface area of the small intestine (41), the short gut syndrome will occur when sufficiently large amounts of intestine have been excised surgically. Growth hormone $(\mathrm{GH})$ may have a stimulatory role in the intestine, and specific $\mathrm{GH}$ receptors have been demonstrated on rat gut epithelial cells. High dose $\mathrm{GH}$ injections increase body weight, distal ileal weight per length of intestine and mucosal height in rats undergoing a $75 \%$ small bowel resection (42). It remains to be determined whether GH may be useful to accelerate intestinal adaptation in persons with the short bowel syndrome.

Intraluminal administration of carbohydrate or lipid increases intestinal lymph flow as well as increasing the number of lymphocytes transported through mesenteric lymph ducts. In long term total parenteral nutrition (TPN) in rats, the number of transported lymphocytes and the ratio of helper:suppressor $\mathrm{T}$ cells in intestinal lymph is lowered (43).

Polyamines play an important role in gastrointestinal mucosal growth (44). Omithine decarboxylase and polyamines are involved in ileal adaptation to malnutrition in postweaned and adult rats (45). There is an early and sustained increase in the abundance of proglucagon mRNA in the ileum of rats after jejunectomy, and this rise is not inhibited by DFMO (an irreversible inhibitor of ornithine decarboxylase activity that blocks adaptive bowel growth after intestinal resection) (46).

The ingestion of food plays an important role in the maintenance of normal small bowel structure and function. The continuity of the epithelial lining occurs by a process called 'restitution'. Restitution of the epithelium occurs quickly after injury, and may be important in the repair of superficial defects in the epithelium that may occur normally during the course of digestion and absorption of food. TPN results in mucosal atrophy even though the total body energy and nitrogen balance is maintained. In TPN-maintained rats, jejunal galactose absorption is inhibited, while absorption of glycine or the dipeptide glycylglycine is unchanged (47). In infant piglets, supplementing TPN with glutamine or glutamic acid does not have an effect on small intestinal protein or DNA content, or on specific activities of lactase, sucrase or maltase in infant piglets (48). In patients on treatment with home parenteral nutrition following near-total enterectomy, peptide YY concentrations are raised, whereas circulating pancreatic glucagon and neurotensin levels remain normal (49). The gut hormones bombesin and neurotensin prevent jejunal mucosal atrophy seen in animals raised on an elemental diet, and bombesin and pentagastrin stimulate pancreatic growth (50). It remains to be established how to present or to minimize the intestinal atrophy that occurs in persons on TPN.

\section{BLOODFLOW AND INTESTINAL ISCHEMIA}

Ornithine decarboxylate activity plays an important role in the repair process that results in complete restoration of mucosal function two days after ischemia-reperfusion injury in rats (51). The reactive hyperemia (which is a local vascular response following release from arterial occlusion) is influenced by peripheral sympathetic nerves, with alpha-adrenergic receptors restricting, and beta-adrenergic receptors enhancing, hyperemia (52). Adenosine is a vasodilator in the canine intestinal mucosa (53). Neuropeptide $\mathrm{Y}$ and peptide $\mathrm{YY}$ may regulate gastrointestinal function by their effects on bloodflow (54).

After a period of hypoxia, the mucosal injury is produced not only during the intestinal ischemia, but also during reperfusion. The postischemic tissue damage is caused by oxygen-derived free radicals which initiate the peroxi- dation of membrane lipids and the subsequent release of chemoattractants; these lead to the accumulation of poly. morphonuclear leukocytes in the tissue. This mucosal injury may be reduced appreciably by a monoclonal antibody that inhibits leukocyte adherence to endothelial cells (55).

Cyclosporin A and FK506 are potent immunosuppressants that prevent rejection in organ transplantation, and may attenuate the tissue injury associated with reperfusion of ischemic tissues. Both of these agents may be important in modulating neutrophil infiltration in acute inflammatory conditions, such as in ischemia/reperfusion (IR) injury in the cat (56). The granulocyte accumulation elicited by IR depends on the expression and/or activation of the leukocyte adhesion glycoprotein CD11/CD18 (57).

The intestinal injury induced by partial ischemia followed by reperfusion is decreased by the intravenous administration of superoxide dismutase so that oxygen free radicals have been postulated to play critical roles in $\mathbb{R}$ injury. Because intestinal injury cannot be inhibited efficiently by superoxide dismutase when complete ischemia is produced, it has been suggested that factors other than superoxide radicals may also play important roles in IR intestinal injury. For example, extracellular diamines may play a critical role in postischemic reperfusion-induced injury of the small intestine in the rat (58). Also, intraluminal pancreatic proteases have been proposed to be important in the development of the $\mathbb{R}$ injury, and intraluminal pancreatic proteases may be involved in the rapid development of mucosal reperfusion injury (59).

Acetylcholine-induced relaxation of vascular smooth muscle is mediated through the release of an endotheliumderived relaxing factor (EDRF). EDRF has been identified as nitric oxide or a closely related molecule derived from the guanidino group of $\mathrm{L}$-arginine. L-glutamine inhibits the release of EDRF from rabbit aorta (60). In the mesenteric arterial bed, nitric oxide formation by the pathway sensitive to an arginine analogue occurs during stimu- 
lation with acetylcholine, but not under basal conditions (61). The importance of nitric oxide formation in the pathogenesis of intestinal ischemia in humans needs to be defined.

The clinical signs and symptoms of intestinal infarction are nonspecific, making early diagnosis difficult. The measurement of creatine kinase isoenzymes may be useful in the diagnosis of intestinal infarction in man (62).

\section{REFERENCES}

1. Heitlinger LA, Sloan HR, DeVore DR, Lee PC, Lebenthal EM, Duffey ME. Transport of glucose polymer-derived glucose by rabbit jejunum. Gastroenterology 1992;102:433-47.

2. Ferraris RP, Lee PP, Diamond JM. Origin of regional and species differences in intestinal glucose uptake. Am J Physiol 1989;251:G689-97.

3. Toloza EM, Lam M, Diamond JM. Nutrient extraction by cold-exposed mice: A test of digestive safety margins. Am J Physiol 1991;261:G608-20.

4. Ferraris RP, Yasharpour S, Lloyd KCK, Mirzayan R, Diamond JM. Luminal glucose concentrations in the gut under normal conditions. Am J Physiol 1990;259:G822-37.

5. Morrill JS, Kwong LK, Sunshine P, Briggs GM, Castillo RO, Tsuboi KK. Dietary $\mathrm{CHO}$ and stimulation of carbohydrases along villus column of fasted rat jejunum. Am J Physiol 1989;256:G158-65.

6. Buddington RK, Chen JW, Diamond JM. Dietary regulation of intestinal brush-border sugar and amino acid transport in carnivores. Am J Physiol 1991;261:R793-801.

7. Malo C. Kinetic evidence for heterogeneity in $\mathrm{Na}^{+}$-D-glucose cotransport systems in the normal human fetal small intestine. Biochim Biophys Acta 1988;938:181-8.

8. Malo C. Separation of two distinct $\mathrm{Na}^{+} / \mathrm{D}$-glucose cotransport systems in the human fetal jejunum by means of their differential specificity for 3-0-methylglucose. Biochim Biophys Acta 1990;1022:8-16.

9. Berteloot A, Malo C, Breton S, Brunette M. Fast sampling, rapid filtration apparatus: Principal characteristics and validation from studies of D-glucose transport in human jejunal brush-border membrane vesicles. J Membr Biol 1991;122:111-25.

10. Malo C, Berteloot A. Analysis of kinetic data in transport studies: New insights from kinetic studies of
The introduction of the ultrasonic pulsed Doppler technique (duplex scanning) for mesenteric bloodflow measurements has made it possible to study the relationship between intestinal function and intestinal bloodflow occurring in health and disease. Such measurements have indicated that the intestinal phase is the major regulator of the postprandial mesenteric bloodflow response in healthy humans, and

$\mathrm{Na}^{+} / \mathrm{D}$-glucose cotransport in human intestinal brush-border membrane vesicles using a fast sampling, rapid filtration apparatus. J Membr Biol 1991;122:127-41.

11. Harig JM, Barry JA, Rajendran VM, Soergel KH, Ramaswamy K. D-glucose and $\mathrm{L}$-leucine transport by human intestinal brush-border membrane vesicles. Am J Physiol 1989;256:G618-23.

12. Meddings JB, DeSouza D, Goel M, Thiesen S. Glucose transport and microvillus membrane physical properties along the crypt-villus axis of the rabbit. J Clin Invest 1990;85:1099-107.

13. Erdman SH, Hart MH, Park JHY, Vanderhoof JA. The intestinal absorption of 3-0-methyl-D-glucose in methotrexate-treated rats: $\mathrm{An}$ in vivo study of small bowel function. J Pediatr Gastroenterol Nutr 1991;13:360-6.

14. Wright EM, Turk E, Zabel B, Mundlos $\mathrm{S}, \mathrm{Dyer}]$. Molecular genetics of intestinal glucose transport. J Clin Invest 1991;88:1435-40.

15. Hediger MA, Coady MJ, lkeda TS, Wright EM. Expression cloning and cDNA sequencing of the $\mathrm{Na}^{+}$/glucose cotransporter. Nature 1987;330:379-81.

16. Hediger MA, Turk E, Wright EM. Homology of the human intestinal $\mathrm{Na}^{+}$/glucose and Escherichia coli $\mathrm{Na}^{+}$/proline cotransporters. Proc Natl Acad Sci USA 1989;86:5748-52.

17. Ikeda TS, Hwang ES, Coady MV, Hirayama BA, Hediger MA, Wright EM. Characterization of $\mathrm{Na}^{+} /$glucose cotransporter cloned from rabbit small intestine. J Membr Biol 1989;110:87-95.

18. Hediger MA, Budarf ML, Emanuel BS, Mohandas TK, Wright EM. Assigment of the human intestinal $\mathrm{Na}^{+}$/glucose cotransporter Gene (SGLT1) to the q11.2-qter region of chromosome 22 . Genomics 1989;4:297-300.

19. Umbach JA, Coady MJ, Wright EM. Intestinal $\mathrm{Na}^{+}$/glucose cotransporter expressed in Xenopus oocytes is electrogenic. Biophys J Biophys Soc 1990;57:1217-24.

20. Stevens BR, Fernandez A, Hirayama that the chemical nature of food determines the mesenteric response pattern (63).

Marathon runners may develop diarrhea and occult intestinal blood loss secondary to intestinal ischemia (64). Intestinal transit time is accelerated by moderate exercise such as jogging and cycling but stool weight, defecation frequency, dietary fibre intake and fluid intake do not change (65).

B, Wright EM, Kempner ES. Intestinal brush border membrane $\mathrm{Na}^{+} /$glucose cotransporter functions in situ as a homotetramer. Proc Natl Acad Sci USA 1990;87:1456-60.

21. Bell GI, Kayano T, Buse JB, et al. Molecular biology of mammalian glucose transporters. Diabetes Care 1990;13:198-208.

22. Coady MJ, Pajor AM, Wright EM. Sequence homologies among intestinal and renal $\mathrm{Na}^{+}$/glucose cotransporters. Am J Physiol 1990;259:C605-10.

23. Riley SA, Warhurst G, Crowe PT, Turnberg LA. Active hexose transport across cultured human Caco- 2 cells: Characterization and influence of culture conditions. Biochim Biophys Acta 1991;1066:175-82.

24. Birnir B, Lee HS, Hediger MA, Wright EM. Expression and characterization of the intestinal $\mathrm{Na}^{+} /$glucose cotransporter in COS-7 cells. Biochim Biophys Acta 1990;1048:100-4.

25. Hirayama BA, Wong HC, Smith CD, Hagenbuch BA, Hediger MA, Wright EM. Intestinal and renal $\mathrm{Na}^{+} /$glucose cotransporters share common structures. Am J Physiol 1991;261:C296-304.

26. Turk E, Zabel B, Mundlos S, Dyer J, Wright EM. Glucose/galactose malabsorption caused by a defect in the $\mathrm{Na}^{+} /$glucose cotransporter. Nature 1991;350:354-6.

27. Hwang ES, Hirayama BA, Wright EM. Distribution of the SGLT1 $\mathrm{Na}^{+}$/glucose cotransporters and mRNA along the crypt-villus axis of rabbit small intestine. Biochem Biophys Res Commun 1991;181:1208-17.

28. Takata K, Kasahara T, Kasahara M, Exaki O, Hirano $\mathrm{H}$.

Immunohistochemical localization of $\mathrm{Na}^{+}$-dependent glucose transporter in rat jejunum. Cell Tissue Res 1992;267:3-9.

29. Haase W, Heitmann K, Friese W, Ollig D, Koepsell H. Characterization and histochemical localization of the rat intestinal $\mathrm{Na}^{+}-\mathrm{D}$-glucose cotransporter by monoclonal 
antibodies. Eur J Cell Biology 1990;52:297-309.

30. Shirazi-Beechey SP, Hirayama BA, Wang Y, Scott D, Smith MW, Wright EM. Ontogenic development of lamb intestinal sodium-glucose cotransporter is regulated by diet. J Physiol 1991;437:699-708.

31. Hediger MA, Mendlein J, Lee HS, Wright EM. Biosynthesis of the cloned intestinal $\mathrm{Na}^{+} /$glucose cotransporter. Biochim Biophys Acta 1991;1064:360-4.

32. Gould GW, Bell GI. Facilitative glucose transporters: an expanding family. TIBS 1990;15:18-23.

33. Thorens B, Cheng ZQ, Brown D, Lodish HF. Liver glucose transporter: A basolateral protein in hepatocytes and intestine and kidney cells. Am J Physiol 1990;259:C279-85.

34. Davidson NO, Hausman AM, Ifkovits $\mathrm{CA}$, et al. Human intestinal glucose transporter expression and localization of GLUT5. Am J Physiol 1992;263:C795-800.

35. Burant CF, Takeda J, Brot-Laroche E, Bell GI, Davidson NO. Fructose transporter in human spermatozoa and small intestine is GLUT5. J Biol Chem 1992;267:14523-6.

36. Fujisawa T, Riby J, Kretchmer N. Intestinal absorption of fructose in the rat. Gastroenterology 1991;101:360-7.

37. Nelis GF, Vermeeren MAP, Jansen W. Role of fructose-sorbitol malabsorption in the irritable bowel syndrome. Gastroenterology 1990;99:1016-20.

38. Fleming SE, Fitch MD, DeVries S, Liu ML, Kight C. Nutrient utilization by cells isolated from rate jejunum, cecum, and colon. J Nutr 1991;121:869-78.

39. Ardawi MSM, Jalalah SM. Effects of hypothyroidism on glucose and glutamine metabolism by the gut of the rat. Clin Sci 1991;81:347-55.

40. Schaerer E, Neutra MR, Krachenhugl JP. Molecular and cellular mechanisms involved in transepithelial transport. J Membr Biol 1991;123:93-103.

41. Weaver LT, Austin S, Cole TJ. Small intestinal length: a factor essential for gut adaptation. Gut 1991;32:1321-3.

42. Shulman DI, Hu CS, Duckett G, Lavallee-Grey M. Effects of short-term growth hormone therapy in rats undergoing $75 \%$ small intestinal resection. J Pediatr Gastroenterol Nutr $1992 ; 14: 3-11$.

43. Tanaka S, Miura S, Tashiro H, et al. Morphological alteration of gut-associated lymphoid tissue after long-term total parenteral nutrition in rats. Cell Tissue Res 1991;266:29-36.

44. McCormack SA, Johnson LR. Role of polyamines in gastrointestinal mucosal growth. Am J Physiol 1991;260:G795-806.

45. Jonas A, Diver-Haber A, Yahav J. Adaptive response of ileal mucosa to malnutrition in the rat: role of polyamines. Acta Physiol Scand 1991;142:387-95.

46. Ulshen MH, Hoyt EC, Fuller CR, Lund PK. Increased ileal proglucagon expression after proximal small bowel resection is not suppressed by DFMO. Gastroenterology 1992;102:A582.

47. Miura S, Tanaka S, Yoshioka M, et al. Changes in intestinal absorption of nutrients and brush border glycoproteins after total parenteral nutrition in rats. Gut 1992;33:484-9.

48. Burrin DG, Shulman RJ, Storm MC, Reeds PJ. Glutamine or glutamic acid effects on intestinal growth and disaccharidase activity in infant piglets receiving total parenteral nutrition. J Parenter Enter Nutr 1991;15:262-6.

49. Andrews NJ, Irving MH. Human gut formone profiles in patients with short bowel syndrome. Dig Dis Sci 1992;37:729-32.

50. Evers BM, Izukura M, Townsend CM, Uchida T, Thompson JC. Differential effects of gut hormones on pancreatic and intestinal growth during administration of an elemental diet. Ann Surg 1990;211:630-8.

51. Fujimoto K, Granger DN, Price VH, Tso P. Ornithine decarboxylase is involved in repair of small intestine after ischemia-reperfusion in rats. Am J Physiol 1991;24:G523-9.

52. Pawlik WW, Hottenstein OD, Jacobson ED. Adrenergic modulation. Am J Physiol 1991;261:G392-400.

53. Sawmiller DR, Chou CC. Adenosine is a vasodilator in the intestinal mucosa. Am J Physiol 1991;261:G9-15.

54. Sheikh SP. Neuropeptide Y and peptide YY: Major modulators of gastrointestinal blood flow and function. Am J Physiol 1991;261:G701-15.

55. Schoenberg MH, Poch B, Younes M, et al. Involvement of neutrophils in postischaemic damage to the small intestine. Gut 1991;32:905-12.

56. Kubes P, Hunter J, Granger DN. Effects of cyclosporin A and FK506 on ischemia/reperfusion-induced neutrophil infiltration in the cat. Dig Dis Sci 1991;36:1469-72.

57. Kurtel H, Tso P, Granger DN. Granulocyte accumulation in postischemic intestine: role of leukocyte adhesion glycoprotein CD11/CD18. Am J Physiol 1992;262:G878-82.

58. Koshi S, Inoue M, Obayashi $\mathrm{H}$, Miyauchi Y. Inhibition of postischemic reperfusion injury of the small intestine by diamine oxidase. Biochim Biophys Acta 1991;1075:231-6.

59. Montgomery A, Borgström A, Haglund U. Pancreatic proteases and intestinal mucosa injury after ischemia and reperfusion in the pig. Gastroenterology 1992;102:216-22.

60. Swierkosz TA, Mitchell JA, Sessa WC, Hecker M, Vane JR. L-glutamine inhibits the release of endotheliumderived relaxing factor from the rabbit aorta. Biochem Biophys Res Commun 1990;172:143-8.

61. Ebeigbe AB, Cressier F, Konneh MK, Luu TD, Criscione L. Influence of $\mathrm{N}^{\mathrm{G}}$-monomethyl-L-arginine on endothelium-dependent relaxations in the perfused mesenteric vascular bed of the rat. Biochem Biophys Res Commun 1990;169:873-9.

62. Fried MW, Murthy UK, Hassig SR, Wood J, Oates RP. Creatine kinase isoenzymes in the diagnosis of intestinal infarction. Dig Dis Sci 1991;36:1589-93.

63. Sieber C, Beglinger C, Jäger K, Stalder GA. Intestinal phase of superior mesenteric artery blood flow in man. Gut 1992;33:497-501.

64. Bounous G, McArdle AH. Marathon runners: the intestinal handicap. Med Hypotheses 1990;33:261-4.

65. Oettle G]. Effect of moderate exercise on bowel habit. Gut 1991;32:941-4. 


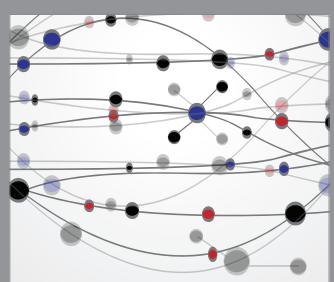

The Scientific World Journal
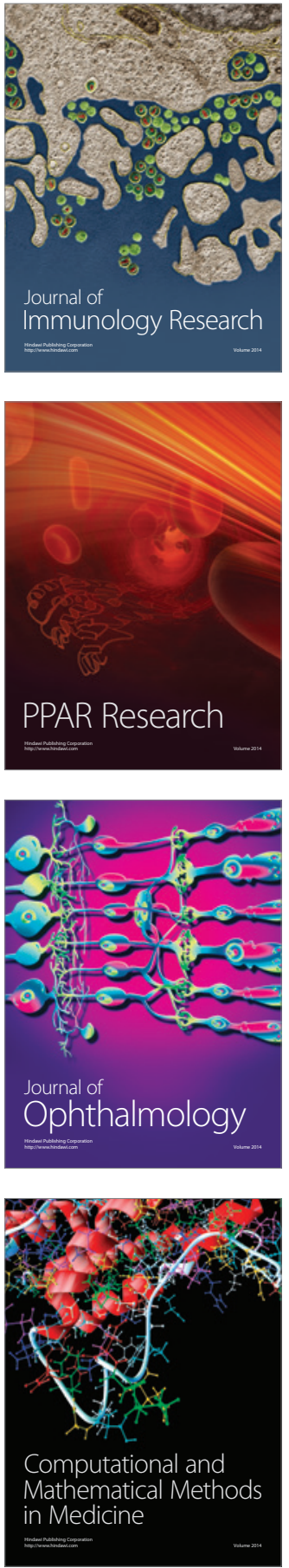

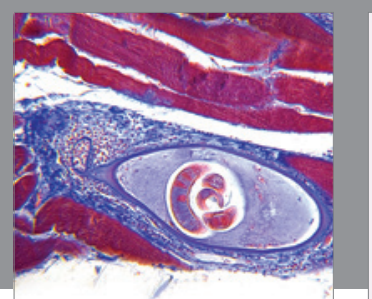

Gastroenterology Research and Practice

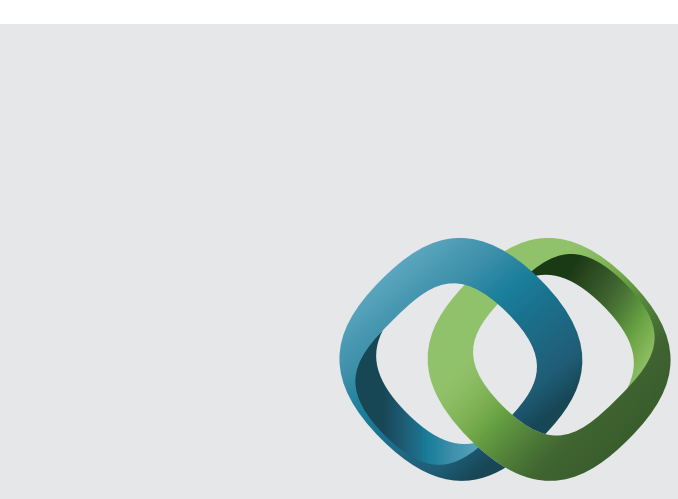

\section{Hindawi}

Submit your manuscripts at

http://www.hindawi.com
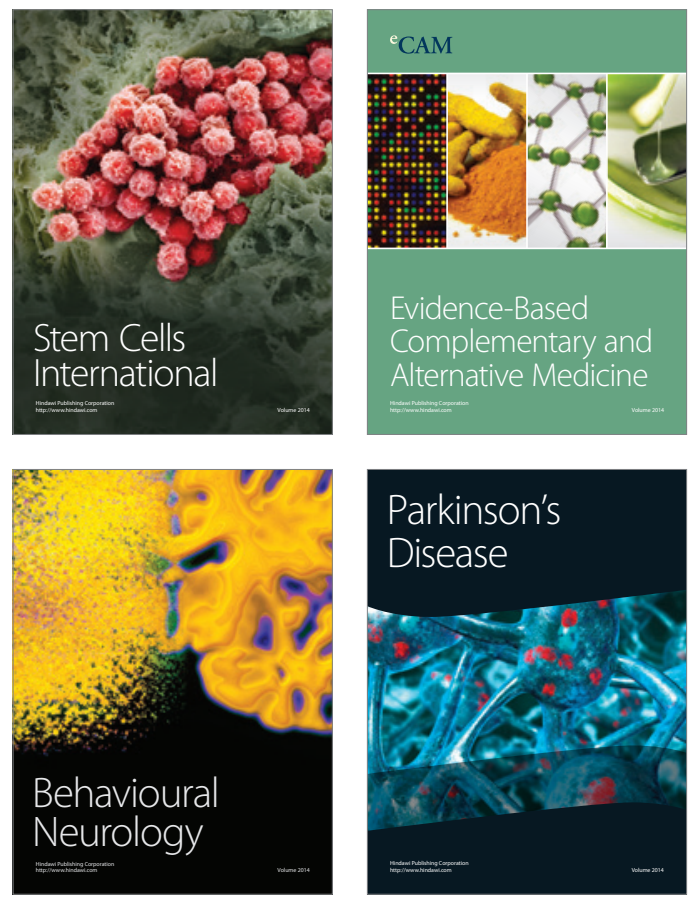
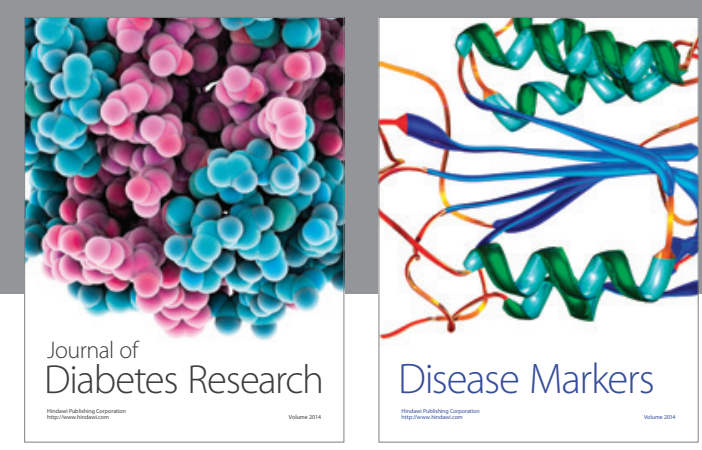

Disease Markers
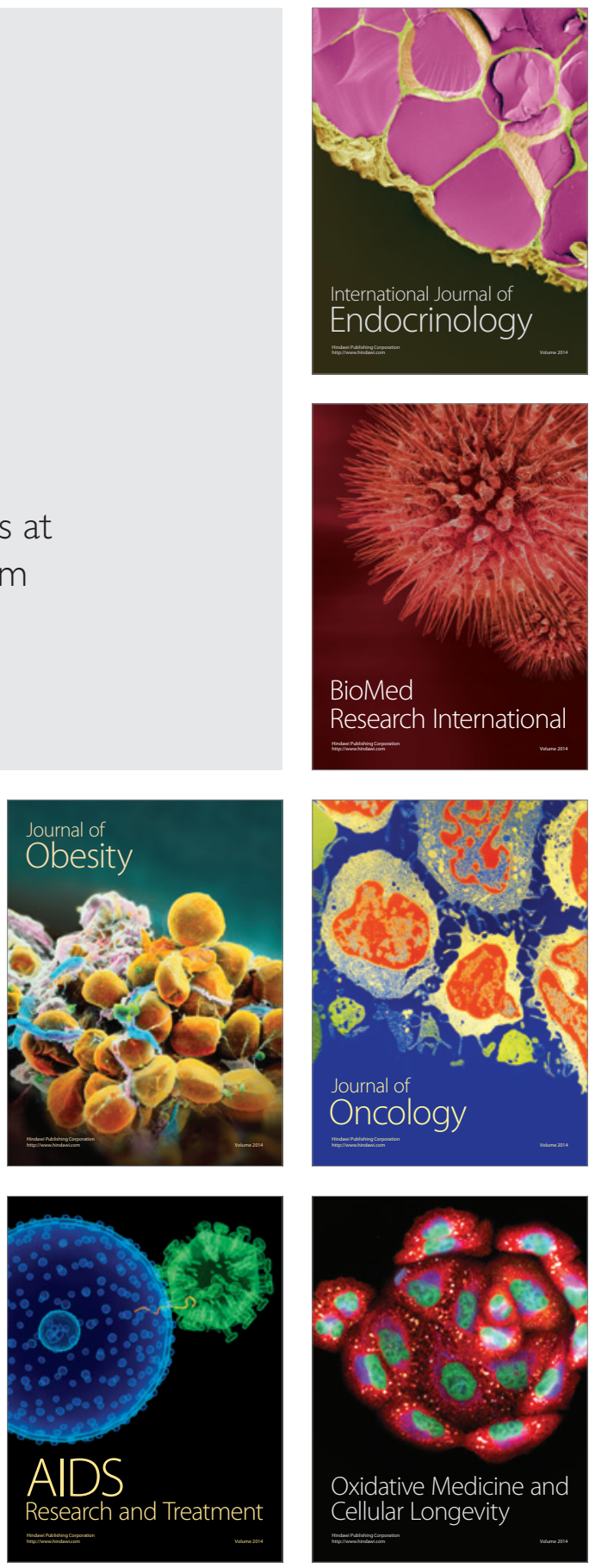